\title{
Comparative Morphological Analysis of Graphene on Copper Substrate obtained by CVD from a Liquid Precursor
}

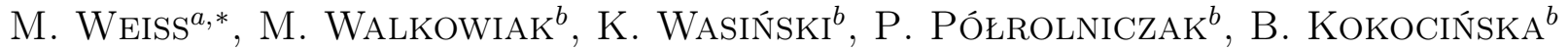 \\ AND W. STRUPIŃSKI ${ }^{c}$ \\ ${ }^{a}$ Institute of Physics, Faculty of Technical Physics, Poznań University of Technology, \\ Piotrowo 3, 60-965 Poznań, Poland \\ ${ }^{b}$ Institute of Non-Ferrous Metals Division in Poznań, Central Laboratory of Batteries and Cells, \\ Forteczna 12, 61-362 Poznań, Poland \\ ${ }^{c}$ Institute of Electronic Materials Technology, Wólczyńska 133, 01-919 Warsaw, Poland
}

(Received August 4, 2016; in final form May 6, 2017)

\begin{abstract}
Graphene film has been produced on untreated $\mathrm{Cu}$ substrate by a chemical vapor deposition technique in ambient pressure with liquid ethanol serving as the carbon precursor. The obtained material has been subjected to morphological study, directly on $\mathrm{Cu}$ substrate, by means of optical microscopy, scanning electron microscopy, atomic force microscopy, and a detailed Raman analysis. As a benchmark material, graphene obtained on $\mathrm{Cu}$ by a conventional CVD from gaseous methane was used. This simple experimental setup has proved to enable obtaining large area graphene samples with nearly $100 \%$ substrate coverage and large domains of one carbon layer. As compared to graphene from gaseous precursor, the presented approach resulted in visibly more defects and impurities. These imperfections are due to more complex precursor molecular structure and lack of $\mathrm{Cu}$ pretreatment with hydrogen, the later cause being easy to eliminate in course of further optimization of the method. The described approach can be regarded as a viable, low-cost, and experimentally simple alternative for the existing techniques of producing large area graphene. By providing direct comparison with the conventional method, the paper's intention is to provide deeper insight and to fill gap in the understanding of mechanisms involved in graphene formation on copper.
\end{abstract}

DOI: 10.12693/APhysPolA.131.1497

PACS/topics: 68.65.Pq, 81.05.ue

\section{Introduction}

Graphene, a two-dimensional monoatomic layer of carbon atoms in a hexagonal array, is nowadays gaining a lot of attention due to its extraordinary mechanical and physical properties [1-3]. Thanks to the wide range of possible graphene applications, such as flexible transparent conductors [4, 5], integrated circuit elements [6], highfrequency transistors $[7,8]$, ultracapacitors [9], battery electrodes [10,11], desalination membranes [12], passivation layers [13] and composite materials [14], there is a strong need to develop scalable and cost-effective production methods. A number of physical and chemical techniques are known that enable production of monoatomic graphene sheets on metallic and non-metallic substrates. One of the most effective, inexpensive methods of depositing high quality graphene onto transition metal substrates, such as $\mathrm{Ni}$ [15], $\mathrm{Pd}$ [16], $\mathrm{Ru}$ [17] or $\mathrm{Cu}$ [18], is chemical vapor deposition (CVD). Among different metals with proved catalytic action towards graphene synthesis, $\mathrm{Cu}$ seems to be the best choice, as thin and flexible

\footnotetext{
* corresponding author; e-mail:

marek.1.weiss@doctorate.put.poznan.pl
}

$\mathrm{Cu}$ foils are available at high purity and low cost. Additionally, the carbon solubility in $\mathrm{Cu}$ at a standard graphene growth temperatures is extremely low, therefore decomposition of carbon precursors form graphene directly on top of $\mathrm{Cu}$ is possible [19].

In spite of the technical simplicity, there is a lot of factors that need to be taken into account so as to produce high quality, large-area graphene film on a rough metal substrate by a CVD process. One of the most critical factors is the selection of carbon precursor either in gaseous, liquid or solid form. Another one concerns a proper substrate, overall purity and reaction parameters like temperature, pressure, etc. Thanks to relatively simple and cheap process of fabrication by CVD, largearea graphene sheets can today be achieved at reasonable cost and in relatively large quantities. This may be an important factor regarding industrial application of CVD-based graphene [20].

Thus far, gaseous carbon precursors have been by far most extensively applied, in spite of a relatively complex experimental setup requiring costly pressure gas containers with appropriate fittings. Presented approach might potentially result in significantly less bulky experimental setup. To this moment, there are a relatively few reports on graphene made by CVD from a liquid carbon precursor, including ethanol. Most of them were published in 
2010 and 2011. In particular, Dong et al. investigated large-size graphene growth on $\mathrm{Cu}$ from ethanol and pentane under atmospheric pressure [21] and found ethanol to be superior in terms of the structure of resulting graphene. Another study concerning graphene on $\mathrm{Cu}$ from methanol, ethanol, and 1-propanol was done by Guermoune et al. [22]. It appeared that all these carbon sources behaved in a similar way and showed a characteristic evolution of the Raman $D$-band integrated intensity in function of annealing temperature. Under investigation was also nickel substrate as a catalyst metal. Miyata et al. [23] presented a simple graphene synthesis from ethanol using so-called "flash cooling". Other relevant papers are related to different liquid precursors. Li et al. [24] described low-temperature growth of graphene $\left(300^{\circ} \mathrm{C}\right)$ on $\mathrm{Cu}$ from benzene. Another liquid carbon precursor found in a recent scientific literature is hexane $[25,26]$. Gao et al. [27] showed the synthesis of S-doped graphene on $\mathrm{Cu}$ versus regular one from hexane. In a recent work, Gan et al. [28] demonstrated a ternary $\mathrm{Cu}_{2} \mathrm{NiZn}$ alloy as a substrate and compared it to $\mathrm{Cu}$ and $\mathrm{Cu} / \mathrm{Ni}$. The authors demonstrated elevated $I_{2 D} / I_{G}$ ratios in comparison with $\mathrm{Cu}$. Common features of the above cited works are: $\mathrm{Cu}$ substrate (with the exception of [23]), hydrogen assistance and the fact that graphene sheets had been transferred onto other substrates (usually $\mathrm{SiO}_{2} / \mathrm{Si}$ ) prior to the actual characterization. In this work we present a comparative analysis of large-area graphene sheets grown on a polycrystalline $\mathrm{Cu}$ foil from two different types of carbon precursors, namely liquid (ethanol) versus conventional gaseous (methane). The CVD reactor setup was intentionally kept as simple as possible and the reaction with liquid ethanol carbon source, in contrast to other papers, was not hydrogen-assisted. Moreover, we performed a detailed and technically more demanding analysis of graphene as grown on $\mathrm{Cu}$ foils, without transferring it to another substrate.

\section{Experimental}

\subsection{Sample preparation}

Graphene deposition on $\mathrm{Cu}$ from ethanol was carried out as follows. $\mathrm{Cu}$ foil (25 $\mathrm{\mu m}$ thick, Hohsen, Japan, $99.9 \%$ ) was rinsed with distilled water, treated by $1 \mathrm{M}$ acetic acid at $40^{\circ} \mathrm{C}$ for $20 \mathrm{~min}$, again rinsed three times with distilled water and finally in acetone (Aldrich, Poland, >99.5\%) for $1 \mathrm{~h}$. At the end, ultrasonic homogenizer (35\% of power for $5 \mathrm{~min}$, UP400S, Hielscher, Germany) was used. Clean $\mathrm{Cu}$ foil sheets were placed in horizontal furnace (PR-25/1800, ITR, Poland) inside the quartz tube and exposed to $10 \mathrm{~mL} \mathrm{~min}{ }^{-1}$ argon flow. The furnace (see Fig. 1) was heated up to $1050{ }^{\circ} \mathrm{C}$ at the heating rate of $10^{\circ} \mathrm{C} \mathrm{min}{ }^{-1}$. $\mathrm{Cu}$ sample was annealed at

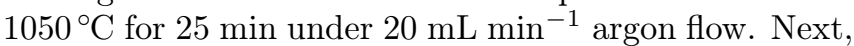
argon flow was decreased to $15 \mathrm{~mL} \mathrm{~min}^{-1}$ and valves 2 and 3 were opened to allow ethanol (about $10.5 \mathrm{~cm}^{2}$ area of evaporation, P.O.Ch., Poland, $>99.5 \%)$ vapor and argon flow inside reactor tube. After another $5 \mathrm{~min}$ the system was switched to argon flow only and the furnace was cooled down at $20^{\circ} \mathrm{C} \mathrm{min}{ }^{-1}$ rate. The obtained $\mathrm{Cu}$ sheets with graphene layers were placed and stored in argon atmosphere. In a separate experiment, graphene deposition on $\mathrm{Cu}$ from methane was carried out according to procedure described in the work [29].

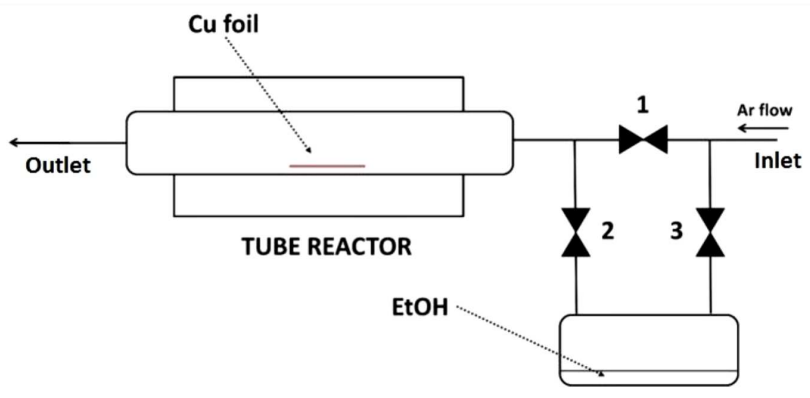

Fig. 1. Scheme of the chemical vapor deposition setup for growing graphene films on $\mathrm{Cu}$ foil.

\subsection{Instrumental analysis}

\subsubsection{Graphene surface morphology}

Optical imaging of graphene on $\mathrm{Cu}$ substrate, after additional annealing $\left(120^{\circ} \mathrm{C}, 30 \mathrm{~min}\right.$ on hot plate), was carried out at ambient conditions using metallurgical microscope (OPMT NJF-120A) with 40-fold magnification. Later, samples were taken to a high vacuum (HV) system with a base pressure below $3 \times 10^{-6} \mathrm{~Pa}$. Scanning electron microscopy (SEM) images were taken by using Zeiss EVO 40 apparatus. Additionally, atomic force microscopy (AFM) studies were performed with the application of Veeco Innova AFM apparatus (Veeco Instruments Inc., USA). The sample's surface topography and related phase-shift signals were recorded in intermittent contact mode (ICM) at ambient temperature and pressure conditions in air. A rectangular PPP-NCLR silicon $\mu-$ cantilever (Nanosensors - NanoWorld AG, Switzerland) with resonant oscillation frequency of about $160 \mathrm{kHz}$ and nominal force constant of about $48 \mathrm{~N} / \mathrm{m}$ was used. The nominal tip radius for PPP-NCLR was less than $10 \mathrm{~nm}$. All the AFM data were analyzed using Gwyddion processing software [30].

\subsubsection{Raman spectroscopy analysis}

The micro-Raman measurements for this study were carried out at ambient conditions in air, using a commercial Raman confocal spectrometer (inVia, Renishaw, UK), equipped with LWD $\times 50$ zoom lens, at fixed excitation wavelength of $514.5 \mathrm{~nm}$ and up to $5 \mathrm{~mW}$ laser power. All Raman scattering experiments required $10 \mathrm{~s}$ CCD detector exposition time.

\section{Results and discussion}

The objective of this study was comparative analysis of two different kinds of large-area graphene samples obtained by $\mathrm{CVD}$ process on polycrystalline $\mathrm{Cu}$ foils from different types of carbon precursors: liquid (ethanol) and 
conventional gaseous (methane) [31]. The latter one, due to a well-established growth process, served as a reference sample in this study. Obviously, each process was performed in a different CVD reactor. High purity metallic substrates for each process came from different manufacturers and were purified in different way. To ensure good quality of graphene domains, the study was done on untouched graphene film attached to the $\mathrm{Cu}$ substrate without transferring to another substrate, like in some other studies [15, 32]. Optical microscopy, SEM and AFM were used to characterize surface morphology of the obtained films. To get more information about the number of graphene layers, homogeneity and defects, local Raman mapping was applied [33].

\subsection{Graphene surface morphology}

Optical microscopy technique was employed to assess the graphene film coverage. The imaging was done after additional annealing of the $\mathrm{Cu}$ substrate covered by graphene film. This simple procedure allowed for rapid oxidation of uncovered metallic substrate and, in consequence, to increase the imaging contrast (dark areas indicate the bare, oxidized $\mathrm{Cu}$ substrate). The annealing time and temperature were chosen experimentally to leave the object of the study untouched. As shown in Fig. 2, it is possible to indicate a number of macroscopic defects and cracks in graphene crystal (dark spots shown by arrows). In some similar optical microscopy studies, such as those presented in works [34-36], no disctinct microscopic details can be observed. However, in another study by Duong et al. [37] focused on probing graphene grain boundaries by means of optical microscopy, similar micro-details as those observed by us were presented. To initiate the oxidation processes of $\mathrm{Cu}$ substrate, the authors used different physical process - ultraviolet irradiation under elevated moisture conditions. Despite a different oxidation process used in our work, the impact on the $\mathrm{Cu}$ substrate and graphene is similar. The authors achieved a very consistent results and considered dark spots as cracks and grain boundaries in graphene crystal [37].

Both images (Figs. 2a and b) reveal good coverage without visible graphene islands [34, 38].

In comparison with the graphene film from methane carbon precursor (Fig. 2b), graphene film from liquid precursor shows much more defects (Fig. 2a). There is a number of possible reasons; the most probable being: (1) more structurally complex liquid precursor, (2) more invasive, chemical treatment of the $\mathrm{Cu}$ substrate and (3) lack of the hydrogen passivation inside the reactor chamber. The last is important due to the efficient termination of graphene's dangling C-bonds and forming more stable $\mathrm{C}-\mathrm{H}$ bonds [39]. This promotes more uniform growth of graphene film. Additionally, in Fig. 2a, small graphene domains are visible (dark straight lines depict cracks, indicated by arrow). Nevertheless, wrinkles and linear folds are natural morphological features of a native metallic substrate. They usually appear due to transferring procedure from transition metal to different substrates, like
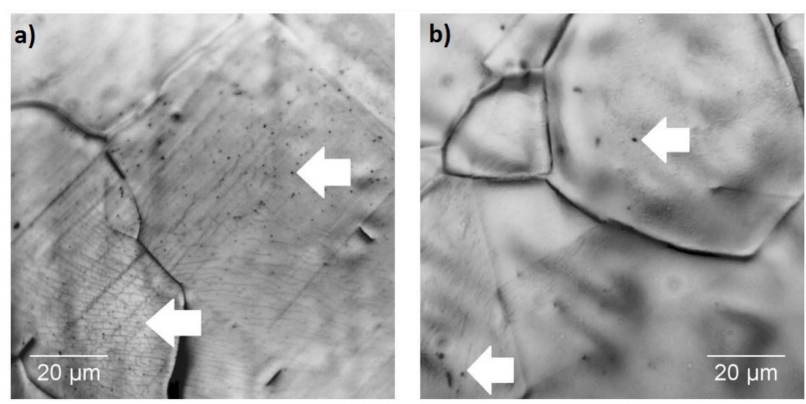

Fig. 2. Images from optical metallurgic microscope: (a) graphene film obtained from liquid ethanol as carbon precursor, (b) graphene film obtained from gaseous methane; dark spots indicated by arrows correspond to oxidized $\mathrm{Cu}$ in places not covered by graphene. Scale bar is $20 \mu \mathrm{m}$.
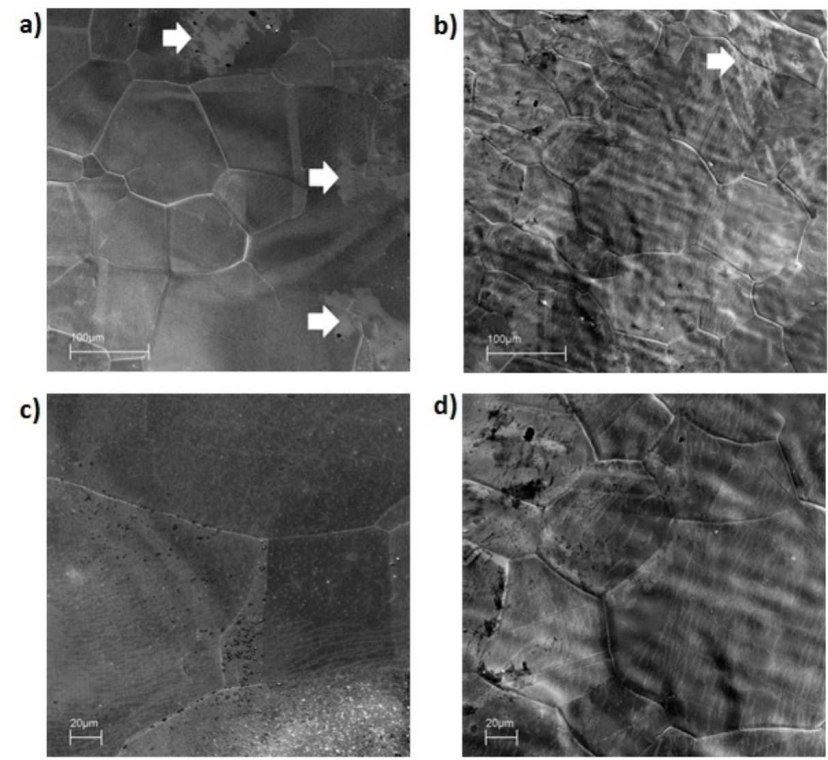

Fig. 3. SEM micrographs of graphene films on Cu substrates; grains on polycrystalline $\mathrm{Cu}$ and cracks (bright color) are visible. Arrows show uncovered $\mathrm{Cu}$ areas: (a) and (c) graphene film obtained from liquid ethanol, (b) and (d) graphene film obtained from gaseous methane.

silicon [40, 41]. This phenomenon may occur as a result of the mismatch of linear expansion coefficients of graphene layer and the $\mathrm{Cu}$ substrate $\left(8 \times 10^{-6} \mathrm{~K}^{-1}[42]\right.$ versus $\left.14 \times 10^{-6} \mathrm{~K}^{-1}[43]\right)$, given that graphene domains are much smaller than single $\mathrm{Cu}$ grain. Cracks might be created in the last stage of CVD process, that is during rapid cooling stage. This stage, as a last part of the CVD process, is necessary to obtain high quality graphene [23].

Similar analysis by means of SEM imaging (Fig. 3) also revealed good homogeneity of the deposited graphene film. Importantly, both samples demonstrated submillimeter scale coverage (Fig. 3a and b). Cracks in graphene crystal structure (bright lines) as well as larger 
discontinuities in deposited layers (shown by arrows) are visible (Fig. 3). Upon closer inspection, graphene film obtained from methane proved to be less defected and more uniform than that from ethanol. Information gained from SEM on $\mathrm{Cu}$ foil are consistent with those reported by other groups: [44] or in supplementary information of [37].

Atomic force microscopy technique has been applied to study topography of the graphene layers (Fig. 4). In this study, AFM operates in the intermittent contact mode and collects data related to topography and phase-shift simultaneously. Both pieces of information allow to confirm findings from optical microscopy and SEM techniques, as well as to determine the height of the graphene directly. Phase shift of signals allow to distinguish between graphene and uncovered $\mathrm{Cu}$ foil in different parts of a sample due to unequal elastic and adhesive mechanical properties of these materials. Thus, as shown in Fig. 4a, b, e and $\mathrm{f}$, it is possible to differentiate between graphene coated region (designated by Gr) and uncoated $\mathrm{Cu}$ (designated by $\mathrm{Cu}$ ). In the phase shift images, it is not possible to directly indicate which part of the map represents which particular material (either $\mathrm{Cu}$ or graphene). In order to assign a particular region to a specific material (in our case graphene) graphene, it is necessary to correlate the phase shift information (Fig. 4a, b, e, f) with the surface topography data (Fig. 4c, d, g, h). a)

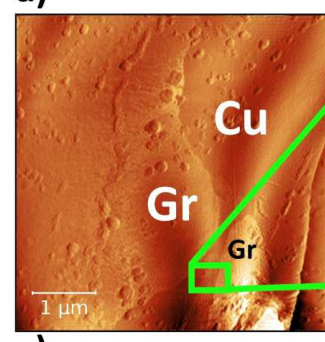

e)

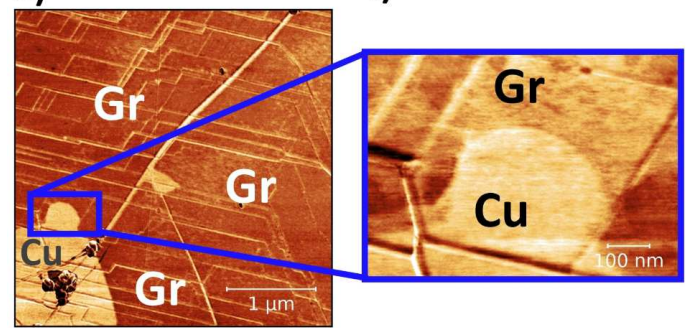

b)

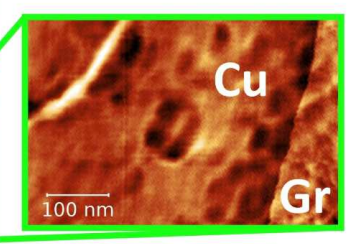

f)

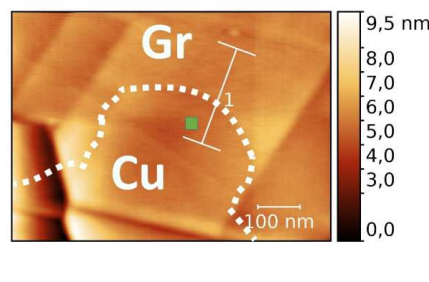

d)
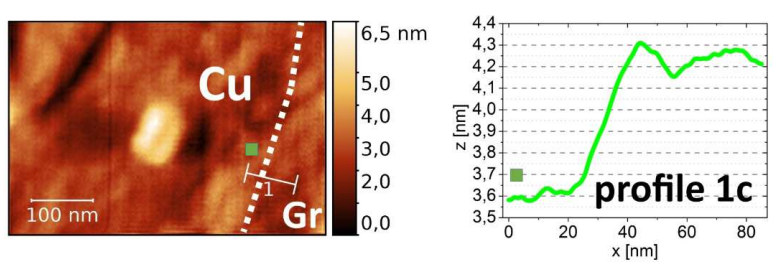

h)

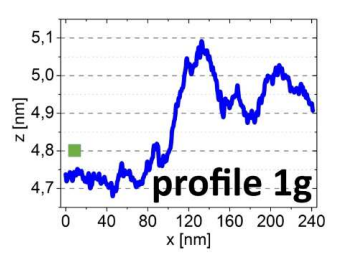

Fig. 4. AFM phase (a, b, e, f) and topography (c, g) images together with topography cross-sections (d, h) of the obtained graphene layers on $\mathrm{Cu}$ substrates: (a)-(d) ethanol precursor, (e)-(h) methane precursor; $\mathrm{Gr}-$ graphene, Cu - copper substrate.

Phase shift AFM image recorded for the ethanolderived graphene (Fig. 4a) reveals a number of small imperfection spots in Gr region, in general accordance with data shown in Fig. 2a and 3c. In comparison to that, analogous $\mathrm{Gr}$ region on the reference methane-derived graphene sample (Fig. 4e) appears to be less defected, also in accordance with Fig. 2b. Apart from that, for methane-derived material, large and distinctive micronscale discontinuities in the graphene crystal are also present. Parallel lines visible in Fig. 4 correspond to terrace topography of the $\mathrm{Cu}$ substrate. Visual differences between $\mathrm{Cu}$ areas on both samples (compare Fig. 4a and e) result clearly from different substrate pretreatment procedures applied to both samples.

Figure $4 \mathrm{c}$ and $\mathrm{g}$ are topographic maps allowing for the assessment of relative heights of the graphene layers. These topographic images correspond to phase images $4 \mathrm{~b}$ and $\mathrm{f}$, cut out from the wider areas $4 \mathrm{a}$ and e, respectively, in places where the boundaries of graphene domains occur. White dotted lines mark these boundaries, otherwise are invisible due to poor contrast, but very clearly visible on the corresponding phase images. It must be pointed out here that even for such a relatively small sectors of the samples, the magnitude of observed heights far exceeds the typical magnitude of one-layer graphene, making the direct observation of the $\mathrm{Cu}-\mathrm{Gr}$ boundary impossible. To enable this observation, topography profiles across the graphene domain boundaries have been done (Fig. $4 \mathrm{~d}$ and $\mathrm{h}$ for the ethanol-derived and methanederived samples, respectively). The profile collection paths are marked in the corresponding $4 \mathrm{c}$ and $\mathrm{g}$ images.

As can be seen, the detected graphene thickness is $c a$. $0.6 \mathrm{~nm}$ for ethanol-derived graphene and $c a .0 .3 \mathrm{~nm}$ for methane-derived graphene. The difference can be assigned to $\mathrm{Cu}$ substrate roughness and to the influence of the AFM tip apex shape. Mean roughness for $1 \mu^{2}$ surface of uncoated $\mathrm{Cu}$ is $7.7 \mathrm{~nm}$ for ethanol-derived and $2.8 \mathrm{~nm}$ for methane-derived sample. Another reason for the observed discrepancy can be traced back to the inherent technical characteristics of the AFM ICM mode, commonly used in graphene visualization [45]. Our AFM measurements were done in a good connection with this 
protocol. Still, we maintain that in both samples single layer graphene is observed. Other groups reported single layer graphene having measured the height of the graphene domain boundaries in the range of $0.3-1.6 \mathrm{~nm}$, thus our measurements fit well enough to justify the graphene monolayer [44-47]. The appearance of more than one-layer graphene would be clearly visible in Fig. 4a,e. Besides, additional top graphene layer would be possible to detect as a decrease of the sample roughness, which is not the case.

\subsection{Raman spectroscopy analysis}

Raman spectroscopy technique emerged as one of the most important tools for non-invasive characterization of graphene. By means of this optical technique it is possible to unambiguously demonstrate the presence of graphene and, in addition, to obtain information about the structure of this material [48]. In case of graphene created on a catalytic metals, such as $\mathrm{Cu}$, Raman measurements are usually done after transferring the graphene layer onto a certain flat substrate, in order to avoid interferences from this metal. The approach adopted in our work relies on measurements performed on the original substrate. In spite of the necessity of dealing with the above mentioned complications, our rare approach allows for the presentation of in situ Raman data, for graphene in its original state.

\subsubsection{Background subtraction procedure}

While working with graphene directly on $\mathrm{Cu}$, due to the strong background signal from the substrate it is vital to remove it from each graphene Raman spectrum by manual subtraction. This was accomplished for each single spectrum and map in this work.

a)

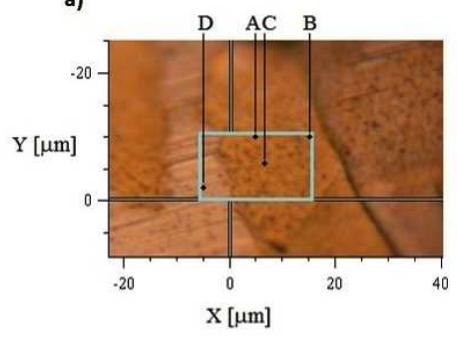

b)

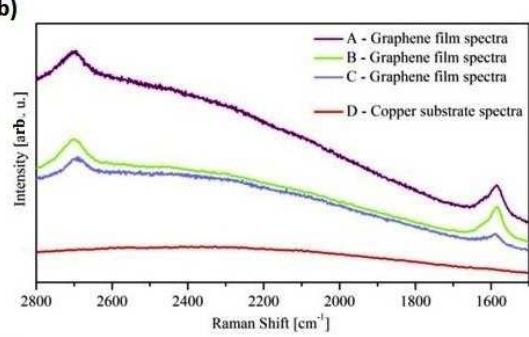

d)

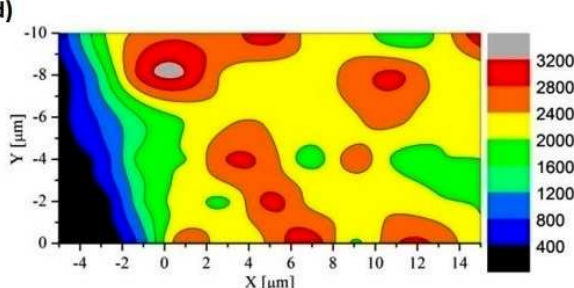

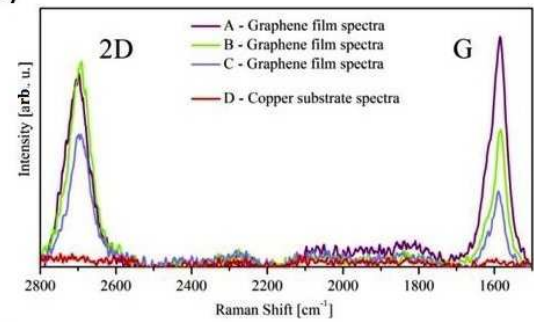

e)

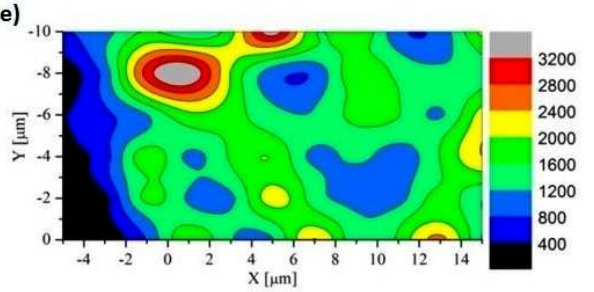

Fig. 5. Exemplary background $\mathrm{Cu}$ signal subtraction procedure: (a) optical image $65 \times 35 \mu \mathrm{m}^{2}$, with the area of the Raman mapping indicated by the internal frame, (b) the Raman spectra collected from points $A, B, C$, and $D$ before the $\mathrm{Cu}$ background subtraction, (c) the Raman spectra collected from points $A, B, C$ and $D$ after the Cu background subtraction, (d) the Raman map of the $2 \mathrm{D}$ band integral intensity $\left[\mathrm{cm}^{-1}\right]$, (e) the Raman map of the G band integral intensity $\left[\mathrm{cm}^{-1}\right]$.

In Fig. 5, demonstrating details of a typical background subtraction procedure, the presented range of the Raman shifts comprises two most characteristic bands related to graphitic materials, namely $2 D$ and $G$. Figure $5 \mathrm{~b}$ presents raw Raman spectra from four different points $A, B, C$, and $D$, indicated in Fig. 5a. Spectra $A, B$, and $C$, after subtraction of the $\mathrm{Cu}$ background signal (spectrum $D$ in Fig. 5b), reveal two bands characteristic for carbon materials, i.e. $2 D$ (the second-order $G^{\prime}$ band) and $G$ (the first-order band). These different points represent graphene with various numbers of atomic layers, which can be concluded from variable $I_{2 D} / I_{G}$ integral intensity ratios [49] (Fig. 5c). Obviously, spectrum $D$ is flat as it comes from the $\mathrm{Cu}$ substrate (Fig. $5 \mathrm{~b}$ and c) and 
it is used in the subtraction procedure. The Raman scattering is an optical and local technique. Gathering of the information is limited to the size of the laser spot. Thus, for a single spectrum, signal is averaged from many focal points of the sample area. Internal frame in Fig. 5a defines the area covered by the obtained Raman maps which are shown in Fig. $5 \mathrm{~d}$ and e (as integral intensities of the $2 D$ and $G$ bands, respectively). Black color corresponds to lack of graphene layer. This is in good agreement with what can be directly observed in the frame on the optical image (Fig. 5a). Thus each Raman map under this study, contains spectral information from $10 \times 20 \mu \mathrm{m}^{2}$ area and is composed of 66 spectra, acquired in $2 \mu \mathrm{m}$ steps at $1000-3000 \mathrm{~cm}^{-1}$ shift range.

3.2.2. Detailed Raman analysis and disorder in the graphene crystals

Figure 6 shows a set of typical graphene spectra taken from random points of both examined samples. Major bands characteristic for single layer graphene, i.e. $2 D, G$, and $D$, are clearly visible. Other bands, like $D+G$ $\left(\approx 2935 \mathrm{~cm}^{-1}\right)$ and $D^{\prime}\left(\approx 1620 \mathrm{~cm}^{-1}\right)$ are also visible, at least for graphene film obtained from ethanol as carbon precursor. Band $2 \mathrm{D}\left(\approx 2690 \mathrm{~cm}^{-1}\right.$, ethanol $)$ is evidently down-shifted by about $30 \mathrm{~cm}^{-1}$ with respect to graphene film produced from methane (red dashed lines in Fig. 6). This offset may be explained in terms

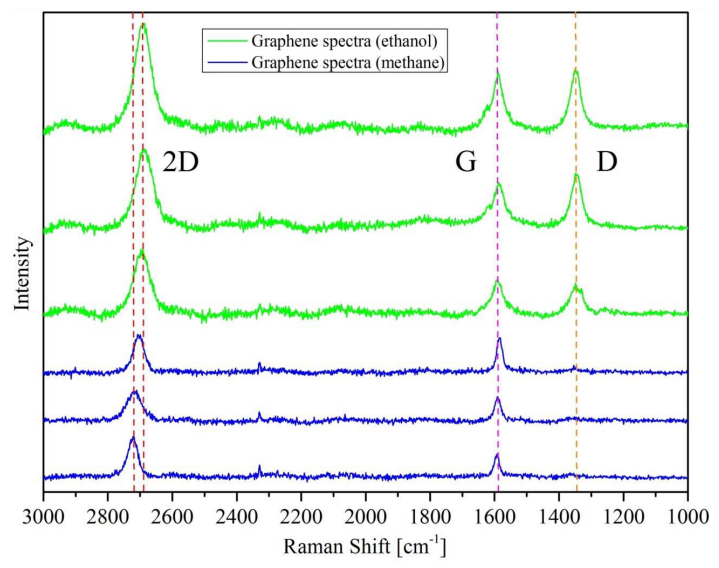

Fig. 6. A set of single spectra recorded at expanded Raman shift range from graphene films obtained from ethanol (green) and methane (blue).

of the measurement on $\mathrm{Cu}$ substrate grains having different crystallographic orientation, due to locally-induced stress in graphene film [50] or because of different reaction temperatures in CVD process [22]. $G$ peak is placed at $\approx 1590 \mathrm{~cm}^{-1}$ and can be attributed to in-plane vibrations of $s p^{2}$-bonded carbon atoms. The integral intensity ratio $2 D / G$ is about 2.5 for graphene produced from methane and about 2.2 for ethanol. These numbers convey information about the number of graphene layers. Thus, for all selected measurement points in Fig. 6 monolayer graphene has been confirmed. The $2 D$ band is characterized by a single Lorentzian peak with full width in a half of the maximum (FWHM) of about $40 \mathrm{~cm}^{-1}$ for "methane" spectra and $50 \mathrm{~cm}^{-1}$ for "ethanol" spectra. The $D$ band is placed at $\approx 1347 \mathrm{~cm}^{-1}$ and is usually used as indicator of defects density in graphite lattice and its allotropes [51]. The $D$ band results from out-of-plane vibrations of $s p^{2}$-bonded carbon atoms. The smaller value of integral intensity of $D$ band, the better in terms of the graphene crystal quality. Judging from optical, SEM and AFM images (Figs. 2-4), graphene film produced from ethanol appears as more defected.

The intensity of $D$ band (Fig. 6) is elevated, while for graphene film produced from methane this effect is almost negligible. This may implicate better electronic, thermal, and mechanical properties [52] as well as generally better quality of the "methane" sample. Since the intensity of the $D$ band is dependent not only on defects but also on the number of graphene layers, it is desirable to check the $D / G$ integral intensity ratio $[53,54]$. The integral intensity ratio $D / G$ is about 0.45 for graphene produced from methane and about 0.85 for ethanol (smaller value means better quality). It is worth to point out that the $D+G\left(\approx 2935 \mathrm{~cm}^{-1}\right)$ and $D^{\prime}\left(\approx 1620 \mathrm{~cm}^{-1}\right)$ bands, observed only for graphene film produced from ethanol, are the second and third defect-induced Raman features. The $D, D^{\prime}$ and $D+G$ bands are not observed in highly crystalline graphene [55]. As we highlighted before, this difference in sample quality can be attributed to the $\mathrm{Cu}$ substrate preparation procedure. It appears to be highly beneficial to passivate the entire surface with $\mathrm{H}_{2}$ inside the CVD reactor [39].

\subsubsection{Analysis of the graphene layers number on the basis of Raman mapping}

One of the most common and useful applications of the Raman scattering technique in relation to graphene is determination of the number of mono-atomic graphene layers. This can be done by comparing the integral intensity ratio of $2 D$ and $G$ bands (Fig. 7) and by analyzing of their FWHM values (Fig. 8). The Raman spectroscopy can clearly distinguish up to 5 monoatomic layers [49]. For more than 5 layers it is hard to distinguish due to the similarity to graphite Raman pattern. Figure $7 \mathrm{a}, \mathrm{c}$ and $7 \mathrm{~b}, \mathrm{~d}$ shows the Raman maps of the integral intensities of $2 D$ and $G$ bands for graphene films obtained from ethanol and methane, respectively. The intensity maps are more uniform and consistent for methane-derived graphene. Maps of the integral intensity ratio $2 D / G$ (Fig. $7 \mathrm{e}, \mathrm{f}$ ) are similar for both samples and are in the range between $1.25-2.00$. These numbers correspond to one-layer and two-layer continuous graphene films. Dark blue areas in Figs. 7e,f (values below 1.0) correspond to multilayer graphene film (graphitic structure). These micrometer-scale areas could play the role of nucleation centers in the process of graphene formation [56]. Blue rectangle frames in Fig. $7 \mathrm{~g}$ and h show the areas of investigation for Figs. 7-9. As shown in Fig. 6, the $2 \mathrm{D}$ band is symmetric, even for defected graphene (green spectra). This feature is characteristic for single layer graphene and can be attributed to the single $\pi$ electron valence band and $\pi^{*}$ conduction band structure [57]. 


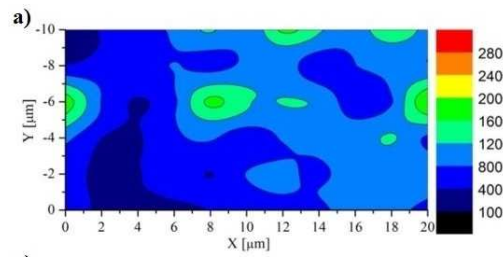

c)
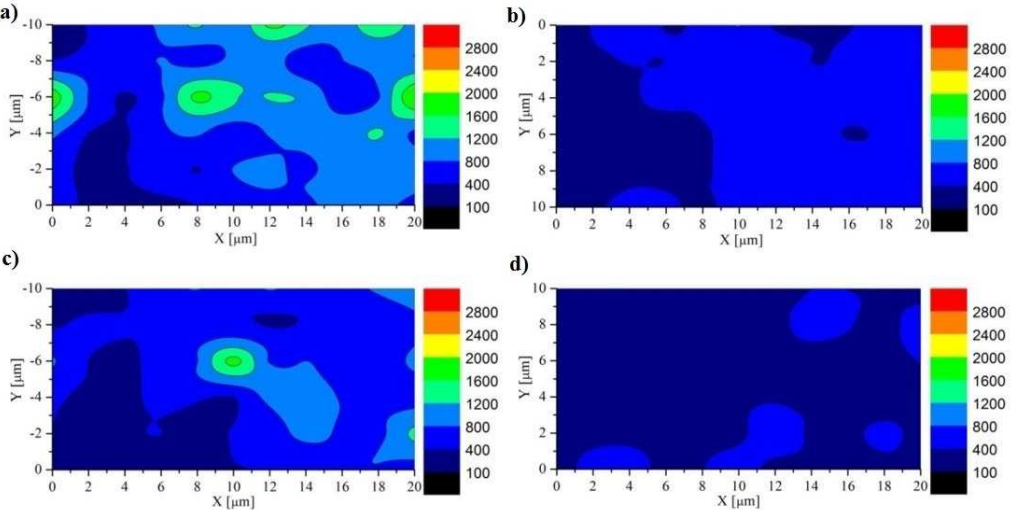
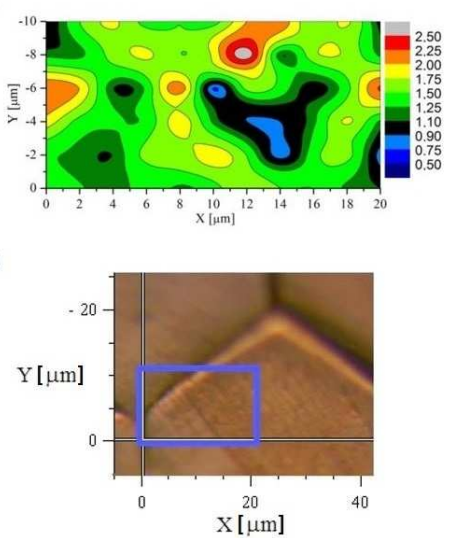
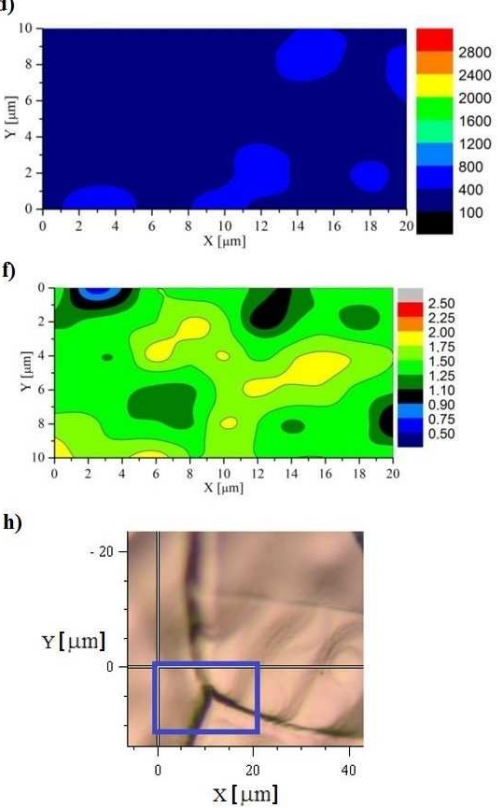

Fig. 7. Raman maps of graphene films obtained from ethanol (left column) and from methane (right column) $\left[\mathrm{cm}^{-1}\right]$ : (a,b) integral intensity of $2 D$ band, (c,d) integral intensity of $G$ band, (e,f) $2 D / G$ integral intensity ratio, (g,h) optical images with blue frames indicating the areas of Raman mapping.

a)

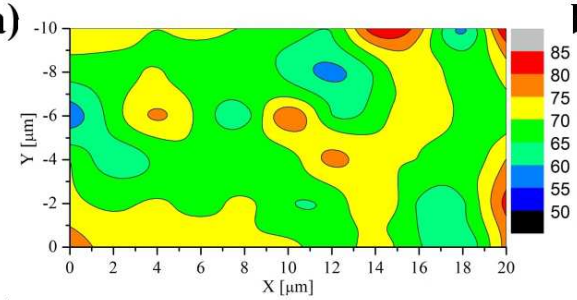

c)

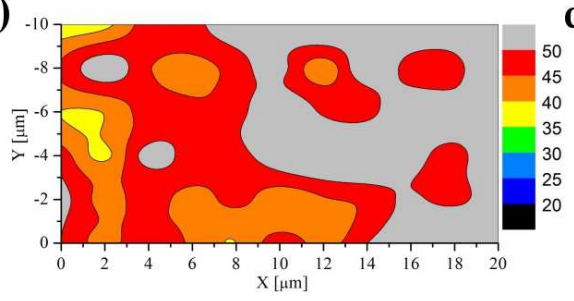

b)

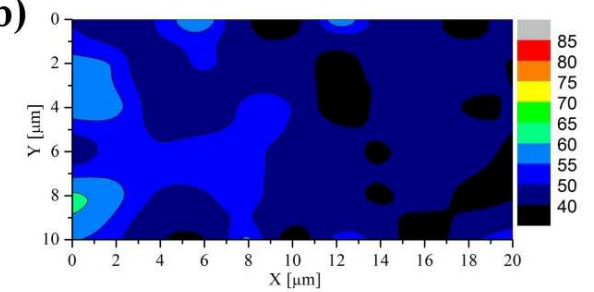

d)

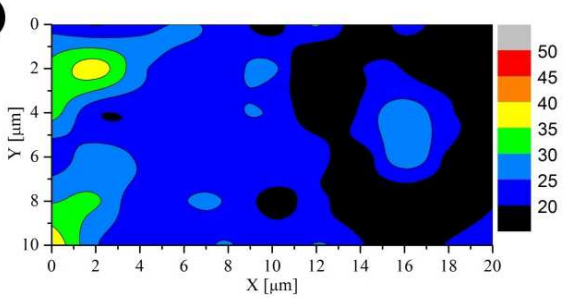

Fig. 8. Raman maps based on the FWHM parameter $\left[\mathrm{cm}^{-1}\right]$ for graphene obtained from ethanol (left column) and methane (right column); (a,b) FWHM of $2 D$ band, (c,d) FWHM of $G$ band.

Nevertheless, as shown in Fig. 8a and b, FWHM of the graphene $2 D$ band is high (broad lines) and is of the order of $60-75 \mathrm{~cm}^{-1}$ for ethanol (Fig. 8a) and $40-55 \mathrm{~cm}^{-1}$ for methane (Fig. 8b), while FWHM corresponding to one-layer graphene is known to be $c a .27 \mathrm{~cm}^{-1}$ [57]. Elevated values of $2 D \mathrm{FWHM}$ for the same laser power end excitation energy, can be interpreted partially in terms of different density of defects as well as unequal strain level $[54,58]$. Moreover, the recorded values may be affected by the $\mathrm{Cu}$ substrate corrugation or $\mathrm{Cu}$ itself (strong background signal). Other explanation can be the existence of local nucleation centers, containing more than one layer of graphene with lateral dimensions smaller than the map resolution.

As suggested by Fig. 7e,f and Fig. 8a,b, higher FWHM values in connection with moderately high $2 D / G$ integral intensity ratio, the examined pieces of $\mathrm{Cu}$ foil may be covered by domains consisting of one or more graphene layers. Such observation was confirmed by AFM analysis (Fig. 4). Thanks to the phase imaging and averaged 
topography cross-sections (Fig. 4d,h) of graphene/Cu interface, the presence of graphene monolayer for both samples was confirmed at least in some parts of the samples, staying in a good agreement with the Raman analysis.

\subsubsection{Stress distribution in graphene crystal}

The application of polycrystalline substrate has severe implications in terms of stress exerted on graphene. Single $\mathrm{Cu}$ crystals, with grain having different crystallographic orientations, will cause uniform or biaxial strain (compression up to $0.3 \%$ ) of the continuous graphene

film [59]. Therefore, graphene obtained on a single $\mathrm{Cu}$ crystal will obviously be more uniform and less defected as compared to frequently used polycrystalline substrate. In the latter case, due to the influence of strain in the graphene layer, both $2 D$ and $G$ bands are shifted with respect to the bands positions observed in relaxed graphene [50]. Figure 9 shows the Raman maps of $2 D$ and $G$ band shifts with respect to relaxed graphene $(2 D$ band: $2680 \mathrm{~cm}^{-1} ; G$ band: $1590 \mathrm{~cm}^{-1}$ ) [60].

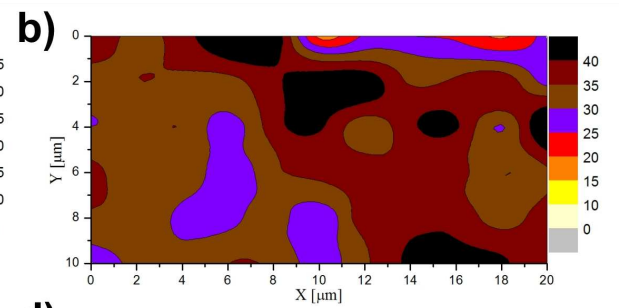

C)
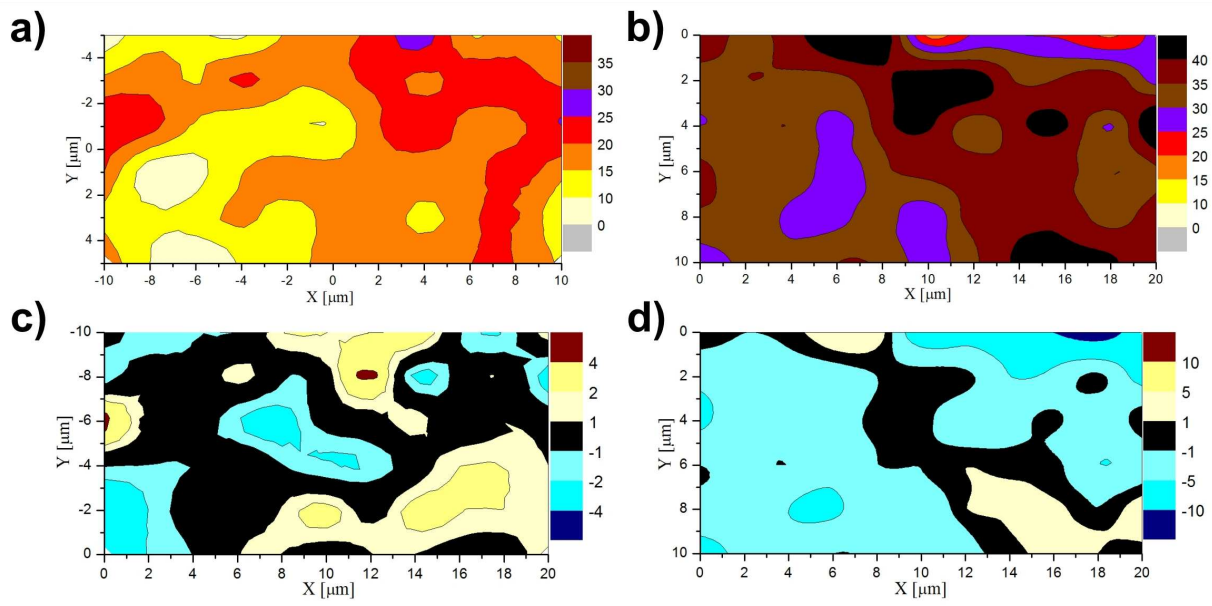

Fig. 9. Raman maps of relative (versus the relaxed graphene) $2 D$ and $G$ shifts $\left[\mathrm{cm}^{-1}\right]$, obtained from ethanol (left) and methane (right): (a,b) $2 \mathrm{D}$ band shift in relation to $2680 \mathrm{~cm}^{-1},(\mathrm{c}, \mathrm{d}) G$ band shift in relation to $1590 \mathrm{~cm}^{-1}$.

Each map includes at least one $\mathrm{Cu}$ grain boundary, so as to verify its possible influence on the band shift (compare Fig. $7 \mathrm{~g}$ and $\mathrm{h}$ ). The influence of grain boundaries is not noticeable. The $2 D$ bands of both ethanolderived and methane-derived samples are up-shifted with respect to the relaxed graphene crystal (Fig. 9a,b). All shift maps (for both $2 D$ and $G$ bands) are characterized by the Gauss distribution. The average shift for the $2 D$ band is $16.3 \pm 0.6 \mathrm{~cm}^{-1}$ for ethanol-derived sample and $34.0 \pm 0.8 \mathrm{~cm}^{-1}$ for methane-derived sample. The differences in the $2 D$ band shift for both samples are clear and have similar nature as shown in Fig. 6. Confirmation of lattice stress requires that both bands, $2 D$ and $G$, be shifted. As can be seen in Fig. 9c and d, the $G$ band shift is too small for both samples. The average value of shift for the $G$ band is $0.2 \pm 0.2 \mathrm{~cm}^{-1}$ for ethanol-derived sample (Fig. 9c) and $-2.4 \pm 0.4 \mathrm{~cm}^{-1}$ for methane-derived sample (Fig. 9d), thus negligible. It is further noteworthy that the local change of graphene crystal thickness will induce mainly the change of the $2 D$ band position [60]. But such behavior may be due to the presence of the $\mathrm{Cu}$ substrate. Therefore, it is hard to conclude about stress exerted on the graphene crystal by $\mathrm{Cu}$.

Lateral graphene crystal domain size has been estimated accordingly to semi-empirical equation given in [61]. According to calculations, the domain size for ethanolderived graphene is $19 \mathrm{~nm}$ while for methane-derived sample the value of $35 \mathrm{~nm}$ has been obtained. These values are comparable with data reported by other works.
For example, $27.3 \mathrm{~nm}$ for graphene on $\mathrm{Cu}$ from hexane as liquid precursor has been reported in the work [27]. Guermoune et al. [22] received higher values (168 nm) for graphene obtained on $\mathrm{Cu}$ from ethanol precursor but in markedly lower temperatures.

\section{Conclusions}

Low-cost, large-area graphene synthesis has been accomplished in a simple CVD tubular reactor from a liquid carbon precursor (ethanol), in argon and without pre-treatment in hydrogen. The article presents a comparative structural study of this graphene versus a similar material obtained in a widely established manner from gaseous precursor (methane). Optical microscopy, SEM, $\mathrm{AFM}$ and Raman spectroscopy mapping techniques were employed to characterize and compare the obtained graphene films directly on the native $\mathrm{Cu}$ substrate. In spite of some interpretational difficulties, such approach allowed to analyze insitu the as prepared graphene films in terms of morphology, continuity, disorder, number of layers and grain size. For the ethanol-based synthesis, single layer graphene has been confirmed by combined AFM and Raman analyses. Coverage by single and double layer graphene was found to be similar to that observed for methane-derived graphene, approaching 100\% of the substrate surface. The ethanol method produces graphene with larger amount of disorder, which can be explained by more complex precursor molecular structure (ethanol versus methane) as well as by the fact that 
the $\mathrm{Cu}$ surface pretreatment by hydrogen was skipped for the sake of the method simplicity. Besides, the technique is far less elaborated as compared to the well-established and highly optimized CVD from gas. In spite of this, it was demonstrated that graphene can be produced on a relatively large scale in simplified experimental setup with the application of liquid precursor. Optimization is strongly needed to reduce the amount of disorder and impurities so as to ensure satisfactory electronic properties.

\section{Acknowledgments}

This work has been financed by the National Science Centre of Poland, grant No. UMO-2011/03/B/ST5/ 01508. Part of work has been supported by the Ministry of Science and Higher Education in Poland under project No. 06/62/DSPB/0217.

\section{References}

[1] A.K. Geim, K.S. Novoselov, Nat. Mater. 6, 183 (2007).

[2] K.S. Novoselov, A.K. Geim, S.V. Morozov, D. Jiang, Y. Zhang, S.V. Dubonos, I.V. Grigorieva, A.A. Firsov, Science 306, 666 (2004).

[3] K.I. Bolotin, K.J. Sikes, Z. Jiang, M. Klima, G. Fudenberg, J. Hone, P. Kim, H.L. Stormer, Solid State Commun. 146, 351 (2008).

[4] H.A. Becerril, J. Mao, Z. Liu, R.M. Stoltenberg, Z. Bao, Y. Chen, ACS Nano 2, 463 (2008).

[5] J.K. Wassei, R.B. Kaner, Mater. Today 13, 52 (2010).

[6] D.A. Areshkin, C.T. White, Nano Lett. 7, 3253 (2007).

[7] Y.M. Lin, C. Dimitrakopoulos, K.A. Jenkins, D.B. Farmer, H.Y. Chiu, A. Grill, P. Avouris, Science 327, 662 (2010).

[8] Y.M. Lin, K.A. Jenkins, A. Valdes-Garcia, J.P. Small, D.B. Farmer, P. Avouris, Nano Lett. 9, 422 (2008).

[9] M.D. Stoller, S. Park, Y. Zhu, J. An, R.S. Ruoff, Nano Lett. 8, 3498 (2008).

[10] C. Wang, D. Li, C.O. Too, G.G. Wallace, Chem. Mater. 21, 2604 (2009).

[11] J. Xiao, D. Mei, X. Li, W. Xu, D. Wang, G.L. Graff, W.D. Bennett, Z. Nie, L.V. Saraf, I.A. Aksay, J. Liu, J.G. Zhang, Nano Lett. 11, 5071 (2011).

[12] M.E. Suk, N.R. Aluru, J. Phys. Chem. Lett. 1, 1590 (2010).

[13] E. Sutter, P. Albrecht, F.E. Camino, P. Sutter, Carbon 48, 4414 (2010).

[14] S. Stankovich, D.A. Dikin, G.H.B. Dommett, K.M. Kohlhaas, E.J. Zimney, E.A. Stach, R.D. Piner, S.T. Nguyen, R.S. Ruoff, Nature 442, 282 (2006).

[15] K.S. Kim, Y. Zhao, H. Jang, S.Y. Lee, J.M. Kim, K.S. Kim, J.H. Ahn, P. Kim, J.Y. Choi, B.H. Hong, Nature 457, 706 (2009).

[16] S.Y. Kwon, C.V. Ciobanu, V. Petrova, V.B. Shenoy, J. Bareno, V. Gambin, I. Petrov, S. Kodambaka, Nano Lett. 9, 3985 (2009)
[17] F.J. Himpsel, K. Christmann, P. Heimann, D.E. Eastman, P.J. Feibelman, Surf. Sci. 115, L159 (1982).

[18] K. Celebi, M.T. Cole, J.W. Choi, N. Rupeshinge, F. Wyczisk, P. Legagneux, N. Rupesinghe, J. Robertson, K.B.K. Teo, H.G. Park, Nano Lett. 13, 967 (2013).

[19] G. Deokar, J. Avila, I. Razado-Colambo, J.L. Codron, C. Boyaval, E. Galopin, M.C. Asensio, D. Vignaud, Carbon 89, 82 (2015).

[20] C. Mattevi, H. Kim, M. Chhowalla, J. Mater. Chem. 21, 3324 (2011).

[21] X. Dong, P. Wang, W. Fang, C.Y. Su, Y.H. Chen, L.J. Li, W. Huang, P. Chen, Carbon 49, 3672 (2011).

[22] A. Guermoune, T. Chari, F. Popescu, S.S. Sabri, J. Guillemette, H.S. Skulason, T. Szkopek, M. Siaj, Carbon 49, 4204 (2011).

[23] Y. Miyata, K. Kamon, K. Ohashi, R. Kitaura, M. Yoshimura, H. Shinohara, Appl. Phys. Lett. 96, 263105 (2010).

[24] Z. Li, P. Wu, C. Wang, X. Fan, W. Zhang, X. Zhai, C. Zeng, Z. Li, J. Yang, J. Hou, ACS Nano 5, 3385 (2011).

[25] A. Srivastava, C. Galande, L. Ci, L. Song, C. Rai, D. Jariwala, K.F. Kelly, P.M. Ajayan, Chem. Mater. 22, 3457 (2010).

[26] C.B. Flores, D.M. López, World J. Condens. Matter Phys. 1, 157 (2011).

[27] H. Gao, Z. Liu, L. Song, W. Guo, W. Gao, L. Ci, A. Rao, W. Quan, R. Vajtai, P.M. Ajayan, Nanotechnology 23, 275605 (2012).

[28] W. Gan, N. Han, C. Yang, P. Wu, Q. Liu, W. Zhu, S. Chen, C. Wu, M. Habib, Y. Sang, Z. Muhammad, J. Zhao, L. Song, ACS Nano 11, 1371 (2017).

[29] G. Lupina, J. Kitzmann, I. Costina, M. Lukosius, C. Wenger, A. Wolff, S. Vaziri, M. Östling, I. Pasternak, A. Krajewska, W. Strupinski, S. Kataria, A. Gahoi, M.C. Lemme, G. Ruhl, G. Zoth, O. Luxenhofer, W. Mehr, ACS Nano 9, 4776 (2015).

[30] D. Nečas, P. Klapetek, Open Phys. 10, 181 (2012).

[31] R. Muńoz, C. Gómez-Aleixandre, Chem. Vap. Deposit. 19, 297 (2013).

[32] Y. Lee, S. Bae, H. Jang, S. Jang, S.E. Zhu, S.H. Sim, Y. Song, B.H. Hong, J.H. Ahn, Nano Lett. 10, 490 (2010).

[33] D. Graf, F. Molitor, K. Ensslin, C. Stampfer, A. Jungen, C. Hierold, L. Wirtz, Solid State Commun. 143 44 (2007)

[34] H. Wang, G. Wang, P. Bao, S. Yang, W. Zhu, X. Xie, W.J. Zhang, J. Am. Chem. Soc. 134, 3627 (2012).

[35] Y. Hao, M.S. Bharathi, L. Wang, Y. Liu, H. Chen, S. Nie, X. Wang, H. Chou, C. Tan, B. Fallahazad, H. Ramanarayan, C.W. Magnuson, E. Tutuc, B.I. Yakobson, K.F. McCarty, Y.W. Zhang, P. Kim, J. Hone, L. Colombo, R.S. Ruoff, Science 342, 720 (2013).

[36] D. Dong, P. Solís-Fernández, H. Hibino, H. Ago, ACS Nano 10, 11196 (2016).

[37] D.L. Duong, G.H. Han, S.M. Lee, F. Gunes, E.S. Kim, S.T. Kim, H. Kim, Q.H. Ta, K.P. So, S.J. Yoon, S.J. Chae, Y.W. Jo, M.H. Park, S.H. Chae, S.C. Lim, J.Y. Choi, Y.H. Lee, Nature 490, 235 (2012). 
[38] Y.A. Wu, A.W. Robertson, F. Schäffel, S.C. Speller, J.H. Warner, Chem. Mater. 23, 4543 (2011).

[39] Y. Yang, W. Rigdon, X. Huang, X. Li, Sci. Rep. 3, 2086 (2013)

[40] Z. Tu, Z. Liu, Y. Li, E. Yang, L. Zhang, Z. Zhao, C. Xu, S. Wu, H. Liu, H. Yang, P. Richard, Carbon 73, 252 (2014)

[41] X. Li, W. Cai, J. An, S. Kim, J. Nah, D. Yang, R. Piner, A. Velamakanni, I. Jung, E. Tutuc, S.K. Banerjee, L. Colombo, R.S. Ruoff, Science 324, 1312 (2009).

[42] D. Yoon, Y.W. Son, H. Cheong, Nano Lett. 11, 3227 (2011).

[43] F.C. Nix, D. MacNair, Phys. Rev. 60, 597 (1941).

[44] M.K. Blees, A.W. Barnard, P.A. Rose, S.P. Roberts, K.L. McGill, P.Y. Huang, A.R. Ruyack, J.W. Kevek, B. Kobrin, D.A. Muller, P.L. McEuen, Nature 524, 204 (2015).

[45] P. Nemes-Incze, Z. Osvatha, K. Kamaras, L.P. Biro, Carbon 46, 1435 (2008).

[46] G. Fisichella, S. Di Franco, P. Fiorenza, R.L. Nigro, F. Roccaforte, C. Tudisco, G.G. Condorelli, N. Piluso, N. Spartŕ, S.L. Verso, C. Accardi, C. Tringali, S. Ravesi, F. Giannazzo, 0.3762/bjnano.4.24Beilstein J. Nanotechnol. 4, 234 (2013).

[47] F. Giannazzo, S. Sonde, V. Raineri, E. Rimini, Nano Lett. 9, 23 (2009).

[48] M.S. Dresselhaus, A. Jorio, M. Hofmann, G. Dresselhaus, R. Saito, Nano Lett. 10, 751 (2010).

[49] A.C. Ferrari, J.C. Meyer, V. Scardaci, C. Casiraghi, M. Lazzeri, F. Mauri, S. Piscanec, D. Jiang, K.S. Novoselov, S. Roth, A.K. Geim, Phys. Rev. Lett. 97 , 187401 (2006).

[50] T.M.G. Mohiuddin, A. Lombardo, R.R. Nair, A. Bonetti, G. Savini, R. Jalil, N. Bonini, D.M. Basko, C. Galiotis, N. Marzari, K.S. Novoselov, A.K. Geim, A.C. Ferrari, Phys. Rev. B 79, 205433 (2009).
[51] F. Tuinstra, J.L. Koenig, J. Chem. Phys. 53, 1126 (1970).

[52] C. Soldano, A. Mahmood, E. Dujardin, Carbon 48, 2127 (2010)

[53] A.C. Ferrari, Solid State Commun. 143, 47 (2007).

[54] L.G. Cançado, A. Jorio, E.H. Ferreira, F. Stavale, C.A. Achete, R.B. Capaz, M.V.O. Moutinho, A. Lombardo, T.S. Kulmala, A.C. Ferrari, Nano Lett. 11, 3190 (2011).

[55] M.A. Pimenta, G. Dresselhaus, M.S. Dresselhaus, L.G. Cançado, A. Jorio, R. Saito, Phys. Chem. Chem. Phys. 9, 1276 (2007).

[56] L. Fan, J. Zou, Z. Li, X. Li, K. Wang, J. Wei, M. Zhong, D. Wu, Z. Xu, H. Zhu, Nanotechnology 23, 115605 (2012)

[57] Y. Hao, Y. Wang, L. Wang, Z. Ni, Z. Wang, R. Wang, C.K. Koo, Z. Shen, J.T.L. Thong, Small 6, 195 (2010).

[58] O. Frank, M. Mohr, J. Maultzsch, C. Thomsen, I. Riaz, R. Jalil, K.S. Novoselov, G. Tsoukleri, J. Parthenios, K. Papagelis, L. Kavan, C. Galiotis, ACS Nano 5, 2231 (2011).

[59] O. Frank, J. Vejpravova, V. Holy, L. Kavan, M. Kalbac, Carbon 68, 440 (2014).

[60] D. Graf, F. Molitor, K. Ensslin, C. Stampfer, A. Jungen, C. Hierold, L. Wirtz, Nano Lett. 7, 238 (2007).

[61] L.G. Cançado, K. Takai, T. Enoki, M. Endo, Y.A. Kim, H. Mizusaki, A. Jorio, L.N. Coelho, R. Magalhăes-Paniago, M.A. Pimenta, Appl. Phys. Lett. 88, 163106 (2006). 